\title{
Learning about research and readership development in STEM education: a systematic analysis of the journal's publications from 2014 to 2018
}

\author{
Yeping $\mathrm{Li}^{1^{*}}$, Jeffrey E. Froyd ${ }^{2}$ and Ke Wang ${ }^{1}$
}

\begin{abstract}
In this editorial, we conduct a systematic review of 144 items published in the International Journal of STEM Education over its first 5-year period from 2014 to 2018. We analyze publication quantities and types, authorship nationality, publication readership, research topic, and top 10 most accessed and top 10 most cited articles over the years. The results provide a snapshot of the research and readership development in multidisciplinary STEM education as an international field.
\end{abstract}

Keywords: Journal publications, Readership, Research development, Systematic review

\section{Introduction}

The International Journal of STEM Education is a multidisciplinary journal in subject-content education that focuses on the study of teaching and learning in science, technology, engineering, and mathematics (STEM). The year of 2018 is the fifth calendar year of publication for the journal that started in August 2014, although it completed only four publication cycle years by the end of July 2018 (Li, 2018a). The counting by calendar year provides an opportunity to systematically collect and analyze data such as publication downloads, citations, author nationality, and research topics. The review provides valuable information about the core focus of this new journal: educational scholarship and readership across the STEM disciplines. We will explore questions that include: What has been published in multidisciplinary STEM education research? Which countries or regions, based on the countries or regions in which the authors were located, contributed publications to multidisciplinary STEM education research? Who accessed and read multidisciplinary STEM education publications? What main topics have emerged in multidisciplinary STEM education research based on the journal's

\footnotetext{
* Correspondence: yepingli@tamu.edu

${ }^{1}$ Texas A\&M University, College Station, TX 77843-4232, USA

Full list of author information is available at the end of the article
}

publications? Which articles in multidisciplinary STEM education research have been highly accessed or cited? Are possible trends identifiable from our analysis?

In this editorial, we examine and summarize the items published in the journal as a window to get a glimpse of the status and trends in scholarship and readership development in multidisciplinary STEM education research. A previous editorial reported on the journal's general performance and published items' disciplinary concentrations on the basis of publication cycle year $(\mathrm{Li}$, 2018a), In contrast, this editorial uses data from the first five years from 2014 to 2018 to systematically analyze (1) numbers and types of items published in the journal, (2) geographic distribution of the authors of the journal's articles, (3) geographic distribution of the journal's readers, (4) topical areas addressed by the articles and possible developing trends, and (5) the top ten articles in terms of access and citation over the five-year period.

\section{What had the journal published over the 5-year period, 2014 to 2018?}

By the end of 2018, the journal had published a total of 144 items, thus averaging 28 items per year. Figure 1 shows the number of items published for each calendar year, from 2014 to 2018. The figure shows the journal started to publish many more items since 2017 (34 and 


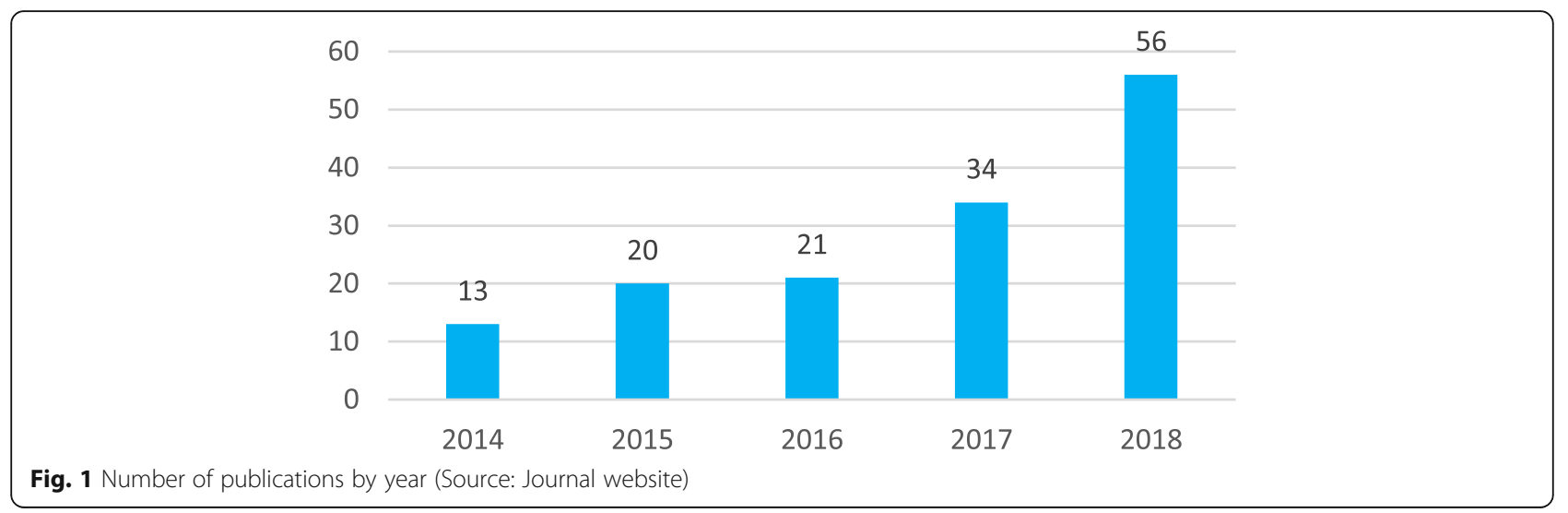

56 publications in the fourth and fifth years, respectively), in comparison to the first three years from August 2014 to the end of 2016 (i.e., 13, 20, and 21 in the first, second, and third years, respectively). We postulated that the growth in the number of the journal publications reflects growing interest in multidisciplinary STEM education scholarship.

Because the journal publishes several types of items, Table 1 shows the breakdown of these 144 publications by type and calendar year.

Table 1 shows that research articles have been the main type of publication each year, followed by short reports and commentaries. There are also a few items as editorials, guest editorials, and errata. These two errata do not really have specific content; instead, they correct results published in a table. As mentioned in a previous editorial ( $\mathrm{Li}, 2018 \mathrm{a})$, research reviews comprise only $1 \%$ of the publications over the 5-year period. Although the relatively short history of STEM education may be one reason for such a shortage, the journal certainly encourages submission of research reviews.

\section{Who published in the journal over the 5-year period, 2014 to 2018 ?}

In addition to numbers of publications, analyzing authorship provides another perspective on activity in multi-disciplinary STEM education scholarship. Because each publication may have either one or multiple authors, there are different ways of analyzing authorship and nationality. One way (method 1) is to consider only the corresponding author's nationality and the first institution affiliation, if multiple institution affiliations are listed. This approach is often valued by some countries and fields, where the scholarly productivity count is not taken as distributed but concentrated. Another approach (method 2) considers every author of a publication. Howard, Cole, and Maxwell (1987) used such an approach with the following formula to quantitatively identify and estimate each author's contribution to a publication (and thus associated institution's productivity), when multiple authors are included in a publication. Tsai and his colleagues used this approach of calculating and estimating each author's contribution to a publication in their sequence of reviews of journal publications in science education (e.g., Lin, Lin, Potvin, \& Tsai, 2019; Tsai \& Wen, 2005). As an example, each publication is given one credit point. For the publication co-authored by two, the first author would be given 0.6 and the second author 0.4 credit point. For this editorial contributed by Li, Froyd, and Wang, the three authors would be credited with scores of $0.47,0.32$, and 0.21 , respectively.

$$
\text { Credit score }=\frac{\left(1.5^{n-i}\right)}{\sum_{i=1}^{n} 1.5^{i-1}}
$$

Clearly, these two approaches differ in terms of what is considered when analyzing authorship. When a publication has only one author, there would be no difference between these two methods. Both methods would

Table 1 Number (percentage) of publications of each type by calendar year

\begin{tabular}{|c|c|c|c|c|c|}
\hline Year & Research articles & Research reviews & Short reports & Commentaries & Other* \\
\hline 2014 & $11(85 \%)$ & & & $1(8 \%)$ & $1(8 \%)$ \\
\hline 2015 & $15(75 \%)$ & $2^{* *}(10 \%)$ & $3(15 \%)$ & & \\
\hline 2016 & $14(67 \%)$ & & $3(14 \%)$ & $3(14 \%)$ & $1(5 \%)$ \\
\hline 2017 & $28(82 \%)$ & & $3(9 \%)$ & $1(3 \%)$ & $2(6 \%)$ \\
\hline 2018 & $44(79 \%)$ & & $5(9 \%)$ & $3(5 \%)$ & $4(7 \%)$ \\
\hline Total & 112 (78\%) & $2(1 \%)$ & $14(10 \%)$ & $8(6 \%)$ & $8(6 \%)$ \\
\hline
\end{tabular}

*Includes editorials, guest editorials, and errata

**Two articles were submitted and published as "research," but they are "reviews" 
allocate the same credit score of 1 for the author. When a publication has multiple authors, there would be big differences in analyzing authorship. The first method focuses on a publication itself but credits only the corresponding author. The second method credits each author of a publication but estimates credit following the order of authorship. However, it ignores situations where in some fields, contributions of the authors are not reflected in the order of authors in the citation. For example, in some fields, it is customary to place the corresponding author last in the list. Each method has advantages and disadvantages; therefore, we use both methods in allocating credit to multiple authors for the purpose of analyzing contributions from different countries. In our analysis, we did not differentiate further across different types of publications. However, we excluded the two errata.

Table 2 shows authors from a broad range of countries have published in the journal, consistent with the name of the journal. However, a vast majority (75\% calculated in either method) of contributions were made by authors from the USA, followed by countries in Europe, Oceania, and Africa. No country in Asia made the top 10 list, except Israel and Turkey depending on how they are identified as in Western Asia or the Middle East as a unique region. Although the results are limited to the journal's first 5 years from 2014 to 2018, they provide a snapshot on activity in STEM education scholarship across different countries.

Further examination of Table 2 reveals that the two methods provide fairly consistent results, but also yield some differences. For example, Australia had more publications if only the corresponding author was considered, but Germany had more publications when coauthors were considered. A similar pattern can be seen for South Africa and Turkey, where South Africa had more publications under method 1, but Turkey under method 2. Such differences could be dramatic if there

Table 2 Comparisons of authorship nationality to 142 publications using two methods

\begin{tabular}{|c|c|c|c|c|c|}
\hline \multirow[t]{2}{*}{ Rank } & \multicolumn{2}{|l|}{ Method 1} & \multirow[t]{2}{*}{ Rank } & \multicolumn{2}{|l|}{ Method 2} \\
\hline & Country & Score (\%) & & Country & Score (\%) \\
\hline 1 & USA & 107 (75.4\%) & 1 & USA & $106.1(74.7 \%)$ \\
\hline 2 & Australia & 5 (3.52\%) & 2 & Germany & $4.6(3.24 \%)$ \\
\hline 3 & Canada & 4 (2.82\%) & 3 & Australia & $4.585(3.23 \%)$ \\
\hline 3 & Germany & $4(2.82 \%)$ & 4 & Canada & $3.6(2.54 \%)$ \\
\hline 5 & Israel & $3(2.11 \%)$ & 5 & Israel & $3(2.11 \%)$ \\
\hline 5 & UK & $3(2.11 \%)$ & 6 & UK & $2.851(2.01 \%)$ \\
\hline 7 & Finland & $2(1.41 \%)$ & 7 & Finland & $2.211(1.56 \%)$ \\
\hline 7 & Netherlands & $2(1.41 \%)$ & 8 & Turkey & $2.072(1.46 \%)$ \\
\hline 7 & South Africa & $2(1.41 \%)$ & 9 & Netherlands & 2.045 (1.44\%) \\
\hline 7 & Turkey & $2(1.41 \%)$ & 9 & New Zealand & 2.045 (1.44\%) \\
\hline
\end{tabular}

were more publications, especially when cross-national collaborations and authorship were involved. The results in Table 2 show that multiple methods should be used when analyzing and comparing publications by country or institution based on authorship.

\section{Who accessed and read the journal over the 5- year period from 2014 to 2018 ?}

Over the years, the journal's publications have been accessed and downloaded by researchers and readers around the world. Figure 2 shows the total number of times journal publications were accessed by year. Overall, there are three dramatic increases of access over these 5 years: (1) from 2014 (6669 times) to 2015 (55,698 times), a $735 \%$ increase or net 49,029 more accesses in 2015; (2) from 2016 (54,883 times) to 2017 (119,095 times), a $117 \%$ increase or net 64,212 more accesses in 2017; and (3) from 2017 (119,095 times) to 2018 (217, 873 times), a $83 \%$ increase or net 98,778 more accesses in 2018. It may be reasonable to assume that the first dramatic increase from 2014 to 2015 is mainly due to the fact that the journal was launched in August 2014, and more readers got to know about the journal in 2015 . However, the second and the third dramatic increases (i.e., from 2016 to 2017, from 2017 to 2018) could be explained by (1) high-quality articles being published in this journal and (2) increasing interest in multidisciplinary STEM education research.

Furthermore, it should be pointed out that the second and the third dramatic increases in access (see Fig. 2) parallel the increases in journal publications over the same time period (see Fig. 1). The pattern of the journal's growth in both publication and access suggests a mutually supportive development of scholarly activity and readership in STEM education over the years.

Going beyond the total number of accesses, it is also important to know who accessed and read the journal. Table 3 shows the top five countries that accessed journal publications by year. It shows the international reach of the journal as well as shifts in access by country. For example, the readers in USA accessed the journal the greatest numbers of times in 2015, 2016, and 2017; however, in 2018, India took the top spot. Brazil was not in the top five in first 3 years in Table 3, but emerged as a country with the third largest number of accesses in 2018.

The development of the journal's readership is contributed by all five continents. Table 4 shows the ranking of five continents in terms of access by year. The Americas had the largest numbers of accesses in 2015 and 2016 but Asia in 2017 and 2018. Taken together, Tables 2, 3, and 4 show the growing international reach of the journal (Li, 2018a). 


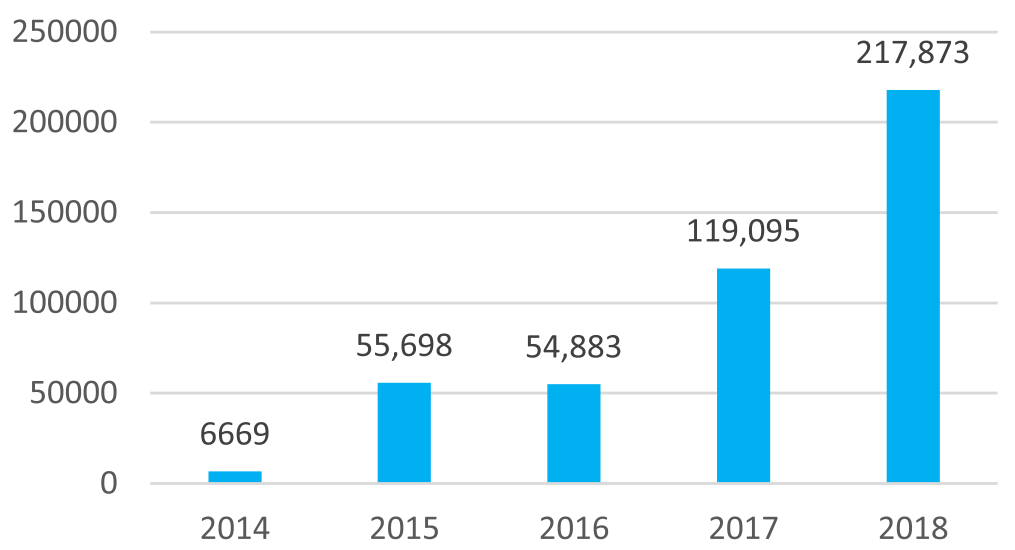

Fig. 2 Number of accesses by year (Source: Springer).

Accesses are defined as the number of times full text or PDF versions of articles are accessed directly from the journal website and SpringerLink. Downloads are defined as HTML, LookInside, PDF, and Epub click. Please note that this does not include article downloads from mirror databases such as PubMed Central

The journal's rapid growth in publication and international readership may be attributed both to the rapidly evolving interest in multidisciplinary STEM education around the globe and to the quality of articles published in this journal (see the "Notes" section at the end of this editorial).

\section{What main topics were published in the journal over the 5-year period from 2014 to 2018?}

To specify and examine research topics published in the journal, we checked several sources of information including the list of topics in calls for proposals from the US National Science Foundation EHR Core Research in STEM education, several conferences in STEM education, and journal publication reviews in selected disciplines in STEM education (e.g., Hynes, Mathis, Purzer, Rynearson, \& Siverling, 2017; Lin et al., 2019; Tsai \& Wen, 2005). We initially generated 11 categories of topics and used the 11 topic categories to test code 100 articles published in another journal. Through test coding and discussions, we eventually developed and used the following seven topic categories for examining and classifying the 142 items (excluding the two errata) published in this journal over the 5-year period from 2014 to 2018.

Table 3 Top five countries that accessed the journal's publications by year

\begin{tabular}{lllll}
\hline Rank & 2015 & 2016 & 2017 & 2018 \\
\hline 1 & USA & USA & USA & India \\
2 & Indonesia & Indonesia & Philippines & USA \\
3 & Turkey & Philippines & Indonesia & Brazil \\
4 & UK & India & India & Philippines \\
5 & Hong Kong & Thailand & Australia & Indonesia \\
\hline
\end{tabular}

Source: Google Analytics
(1) K-12 teaching, teacher, and teacher education in STEM (including both pre-service and in-service teacher education);

(2) Post-secondary teacher and teaching in STEM (including faculty development, etc.);

(3) K-12 STEM learner, learning, and learning environment;

(4) Post-secondary STEM learner, learning, and learning environments (excluding pre-service teacher education);

(5) Policy, curriculum, evaluation, and assessment in STEM education (including literature review about a field in general);

(6) Cultural, social, and gender issues in STEM education; and

(7) History, epistemology, and perspectives about STEM and STEM education.

It should be pointed out that we assigned each publication to only one topic, following other researchers' journal publication analyses (e.g., Lin et al., 2019). When there were cases that more than one topic could have been used, a decision was made in choosing and assigning a topic. The agreement between two coders for all 142 publications was $89 \%$. When topic coding discrepancies occurred, a final decision was reached after discussion.

Table 4 The journal's access ranking across five continents by year

\begin{tabular}{lllll}
\hline Rank & 2015 & 2016 & 2017 & 2018 \\
\hline 1 & Americas & Americas & Asia & Asia \\
2 & Asia & Asia & Americas & Americas \\
3 & Europe & Europe & Europe & Europe \\
4 & Oceania & Oceania & Africa & Oceania \\
5 & Africa & Africa & Oceania & Africa \\
\hline Source: Google Analytics & & &
\end{tabular}

Source: Google Analytics 
Table 5 shows the annual number of publications in each of the seven categories and the percentage of publications in that category for the year. Each year, the topic of "policy, curriculum, evaluation, and assessment in STEM education" was the category with the most publications. This topic thus had the most publications for the 5year total. Cumulatively, over 142 publications, the topic with the second most publications was a tie between " $\mathrm{K}$ 12 teaching, teacher, and teacher education" and "K-12 learner, learning, and learning environment." The results likely suggest the research community had a broad interest in both teaching and learning in K-12 STEM education. On an annual basis, the topics with the second or third most publications varied across the 5 -year period.

Table 5 shows there was a tie between two topics with the fourth most cumulative publications, "post-secondary teacher \& teaching" and "post-secondary learner \& learning." Also, the number of publications in these two areas combined was high over the last 2 years. This may suggest a growing interest in post-secondary STEM learning and teaching. Further for the topic "culture, social, and gender issues in STEM education," there were no publications for the first 3 years, but it was the topic with the third most publications in 2017 and 2018, with a focus "on cultural, social, and gender issues in STEM education" such as STEM identity and students' career choices in STEM. This may also suggest a growing interest in this topic. It would be interesting to see how these publication patterns with respect to these research topics evolve in the future.

\section{Which publications were the top 10 most accessed or cited over the 5-year period from 2014 to $2018 ?$}

With the data from Springer, we were able to rank publications in terms of access and citations. Tables 7, 8, and 9 in the Appendix show the top 10 publications most frequently accessed in each year. In general, there are no obvious patterns across these tables. The publications that made the top 10 most accessed list each year vary in terms of how many were new publications in that year and how many were from previous years (e.g., two previous publications in 2015, seven in 2016, six in 2017, and five in 2018). Those publications from previous years also show various changes in ranking on the lists. It is likely that both publications each year and readers' interest have been evolving, and several variations contributed to such diverse results.

We synthesized results from Tables 7, 8, and 9 in the Appendix to determine publications most accessed in multiple years and found 10 publications. One publication was in the top 10 lists for 4 years, four publications for 3 years, and five publications for 2 years. In many journals, some publications are the most accessed overall and most accessed for multiple years. The synthesis shows that the same is true for the International Journal of STEM Education. We took a further look at research topic areas for each of the 10 publications that made the top 10 most accessed lists 2 or more years, and found that three are in "K-12 teacher \& teaching," one in "post-secondary teacher \& teaching," two in "K-12 learner \& learning," two in "policy, curriculum, and assessment," and two in "history, perspectives of STEM." Although discerning specific patterns is difficult, K-12 STEM education (topics "K-12 teacher \& teaching" and "K-12 learner \& learning") had sustained interest from readers with five out of these 10 publications in these topic areas. The observation aligns with the number of cumulative publications on these topics (see Table 5) . However, the topic "policy, curriculum, and assessment," which was the topic with the most publications, has only two publications that made to the top 10 most accessed lists in multiple years. These diverse results likely suggest that STEM education, as a field, is still undergoing tremendous development.

Table 6 shows the top 10 most cited publications by the end of 2018. The middle column shows the title and the number of years the title appeared in the top 10 most accessed list. It is understandable that none of these publications is from the years of 2017 and 2018, as accumulating citations takes time. Additionally, we checked this list in terms of the number of times an article appeared in the top 10 most accessed list. It is interesting, but not so surprising, that some publications

Table 5 Frequencies and percentages of research topic distributions over the 5 years

\begin{tabular}{|c|c|c|c|c|c|c|}
\hline Research topic & 2014 & 2015 & 2016 & 2017 & 2018 & Total \\
\hline $\mathrm{K}-12$ teacher and teaching & $2^{3}(15.4 \%)$ & $4^{3}(20 \%)$ & $4^{2}(20 \%)$ & $3(8.8 \%)$ & $4(7.3 \%)$ & $17^{2}(12 \%)$ \\
\hline Post-sec teacher and teaching & $1(7.7 \%)$ & $1(5 \%)$ & $2(10 \%)$ & $6^{2}(17.6 \%)$ & $3(5.5 \%)$ & $13(9.2 \%)$ \\
\hline K-12 learner and learning & $4^{1}(30.8 \%)$ & $5^{2}(25 \%)$ & $1(5 \%)$ & $1(2.9 \%)$ & $6^{3}(10.9 \%)$ & $17^{2}(12 \%)$ \\
\hline Post-sec learner and learning & $1(7.7 \%)$ & $1(5 \%)$ & 0 & $3(8.8 \%)$ & $8^{2}(14.5 \%)$ & $13(9.2 \%)$ \\
\hline Policy, curri., and assessment & $4^{1}(30.8 \%)$ & $9^{1}(45 \%)$ & $10^{1}(50 \%)$ & $16^{1}(47.1 \%)$ & $25^{1}(45.5 \%)$ & $64^{1}(45.1 \%)$ \\
\hline Culture, social, and gender & 0 & 0 & 0 & $4^{3}(11.8 \%)$ & $6^{3}(10.9 \%)$ & $10(7 \%)$ \\
\hline History, perspectives of STEM & $1(7.7 \%)$ & 0 & $3^{3}(15 \%)$ & $1(2.9 \%)$ & $3(5.5 \%)$ & $8(5.6 \%)$ \\
\hline
\end{tabular}


Table 6 Top 10 most cited publications by the end of 2018

\begin{tabular}{|c|c|c|}
\hline Rank & $\begin{array}{l}\text { Title (number of times appeared in the top } 10 \text { most } \\
\text { accessed list) }\end{array}$ & $\begin{array}{l}\text { Year of } \\
\text { publishing }\end{array}$ \\
\hline 1 & A conceptual framework for integrated STEM education (3) & 2016 \\
\hline 2 & STEM education K-12: perspectives on integration (3) & 2016 \\
\hline 3 & $\begin{array}{l}\text { Research trends on argumentation in science education: a } \\
\text { journal content analysis from } 1998 \text { to } 2014 \text { (2) }\end{array}$ & 2015 \\
\hline 4 & $\begin{array}{l}\text { The importance of context: an exploration of factors } \\
\text { influencing the adoption of student-centered teaching } \\
\text { among chemistry, biology, and physics faculty (2) }\end{array}$ & 2015 \\
\hline 5 & $\begin{array}{l}\text { STEM learning through engineering design: fourth-grade } \\
\text { students' investigations in aerospace (3) }\end{array}$ & 2015 \\
\hline 6 & $\begin{array}{l}\text { Disciplinary integration of digital games for science learning } \\
(0)\end{array}$ & 2015 \\
\hline 7 & $\begin{array}{l}\text { An exploratory study of informed engineering design } \\
\text { behaviors associated with scientific explanations (0) }\end{array}$ & 2015 \\
\hline 8 & $\begin{array}{l}\text { Planning and carrying out investigations: an entry to } \\
\text { learning and to teacher professional development around } \\
\text { NGSS science and engineering practices (2) }\end{array}$ & 2014 \\
\hline 9 & $\begin{array}{l}\text { The role of visual representations in scientific practices: from } \\
\text { conceptual understanding and knowledge generation to } \\
\text { "seeing" how science works (3) }\end{array}$ & 2015 \\
\hline 10 & $\begin{array}{l}\text { Describing undergraduate STEM teaching practices: a } \\
\text { comparison of instructor self-report instruments }(0)\end{array}$ & 2015 \\
\hline
\end{tabular}

were both highly accessed and highly cited. At the same time, three publications made this top 10 most cited list, but never appeared on a top 10 most accessed list. The result suggests that the most accessed publications and the most cited publications provide us two lenses to learn about readers' and researchers' interests.

If taking a further look at these publications in Table 6 in terms of research topic areas, we found that five are in "policy, curriculum, and assessment" (topic 5), a topic area with the most publications in the journal over the 5-year period (see Table 5). The results likely suggest that researchers shared similar interest, as a community, on research topics in terms of what received the most attention in publications and citations.

\section{Coda}

The systematic analysis of publications in the International Journal of STEM Education from 2014 to 2018 reveals tremendous development in terms of both publications and readership. While there are demonstrable increases in terms of quantity, the evidence, especially on citations and access, suggests an on-going elevation on the quality of publications. Analysis of publications in terms of research topics, albeit with the limited number of publications, showed the development of STEM education as a field in its early stage (Li, 2014, 2018b). Specifically, with the rapid changes in STEM education internationally, it is often difficult for researchers to gauge interests of researchers and readers. The analyses of the top 10 most accessed and top 10 most cited publications may thus help uncover not only possible trends in research development, but also possible consistencies and inconsistencies in terms of scholarly interest and attention for both authors and readers. Such information should be helpful to the research community in thinking about and reflecting on possible research development. At the same time, the results of this analysis also suggest the need and importance of analyzing publications in other journals to examine and document the status and development trends in STEM education research.

In many ways, the analysis shows trends beyond the journal. For example, it is interesting that Asia had the most dramatic increases in readership about STEM education over the past 5 years (see Table 4), but publications in the journal from Asia were very limited over the same time period (see Table 2). The contrast suggests that although scholarship in STEM education started in the USA, not Asia, increased interest in scholarship in STEM education in Asia may likely fuel an increase in research productivity in STEM education in the near future.

We want to take this opportunity to thank all authors, reviewers, and readers for their contributions and support. We are happy to learn from this review that the journal has drawn authors and readers from all over the world. We cannot be happier if this journal also serves as a platform to help "fuel" research development in STEM education in all five continents. We sincerely hope that the journal will continue its growth as a gathering place for many more international researchers and readers in STEM education to enjoy.

\section{Notes}

As reported before (Li, 2018a), the International Journal of STEM Education has been selected and reviewed in the Web of Science's Emerging Sources Citation Index (ESCI) beginning in early 2018, in addition to other important indexing services including Scopus, Google Scholar, and almost 20 other data searching and indexing services. Furthermore, analysis of citations of the journal's publications is ongoing. The initial analysis of citations based on Springer Nature Insights data shows there were a total of 417 citations for the 142 publications by the end of 2018 . This achievement reflects the high quality of the articles that authors have contributed to the multidisciplinary field of STEM education internationally.

In a related note, another new journal, Journal for STEM Education Research (see https://www.springer.com/41979), was launched as an interdisciplinary education research journal in STEM education (Li, 2018b). The journal published only nine items as the first double issue in December 2018 but already had 5147 downloads in 2018 from SpringerLink alone. In comparison to this journal's first year access (i.e., 6669 in 2014 on 13 items published in that year), the Journal for STEM Education Research enjoyed significant access in its first year. Its number of downloads provides another indication of the rapid growth of the international field of STEM education. 


\section{Appendix}

Table 7 Top 10 most accessed publications in 2014 and in 2015

\begin{tabular}{lll}
\hline Rank & Most accessed in 2014* & Most accessed in 2015 \\
\hline $1 \quad \begin{array}{l}\text { A comparative analysis of the relationship between learning styles } \\
\text { and mathematics performance (2014) }\end{array}$ & $\begin{array}{l}\text { = A comparative analysis of the relationship between learning styles and } \\
\text { mathematics performance (2014)** }\end{array}$
\end{tabular}

2 The 23rd ICMI study: primary mathematics study on whole numbers (2014)

+ Planning and carrying out investigations: an entry to learning and to teacher professional development around NGSS science and engineering practices (2014)

3 International Journal of STEM Education-a platform to promote STEM education and research worldwide (2014)

The landscape of PreK-12 engineering online resources for teachers: global trends (2015)

$4 \quad$ Investigation about representations used in teaching to prevent misconceptions regarding inverse proportionality (2014)

Learning to teach scientific practices: pedagogical decisions and reflections during a course for pre-service science teachers (2015)

5 Developing a computer-based assessment of complex problem solving in chemistry (2014)

Exploring variation in measurement as a foundation for statistical thinking in the elementary school (2015)

6 Meteorology meets engineering: an interdisciplinary STEM module for middle and early secondary school students (2014)

7 Mathematics and biology teachers' tacit views of the knowledge required for teaching: varying relationships between CK and PCK (2014)

8 Diffusion of research-based instructional strategies: the case of SCALEUP (2014)

9 Exploring the dynamics of organizational learning: identifying the decision chains science and math faculty use to plan and teach undergraduate courses (2014)

Teachers' perceptions of students' mathematical work while making conjectures: an examination of teacher discussions of an animated geometry classroom scenario (2015)

Research trends on argumentation in science education: a journal content analysis from 1998 to 2014 (2015)

10 Understanding of high-achieving science students on the nature of science (2014)

STEM learning through engineering design: fourth-grade students' investigations in aerospace (2015)

The role of visual representations in scientific practices: from conceptual understanding and knowledge generation to "seeing" how science works (2015)

The importance of context: an exploration of factors influencing the adoption of student-centered teaching among chemistry, biology, and physics faculty (2015)

*Access counts only in that specific year, not accumulated from previous year(s)

**Title (publishing year), the publication in italic means that it was published in a previous year; " $=$ " the same rank, " $+"$ rank up, " $-"$ rank down. The same notations are used in Tables 8 and 9

Table 8 Top 10 most accessed publications in 2016 and in 2017

\begin{tabular}{|c|c|c|}
\hline Rank & Most accessed in 2016 & Most accessed in 2017 \\
\hline 1 & STEM education K-12: perspectives on integration (2016) & + A conceptual framework for integrated STEM education (2016) \\
\hline 2 & A conceptual framework for integrated STEM education (2016) & - STEM education K-12: perspectives on integration (2016) \\
\hline 3 & $\begin{array}{l}\text { The teachers' role in developing, opening, and nurturing an inclusive STEM- } \\
\text { focused school (2016) }\end{array}$ & + The eight essential elements of inclusive STEM high schools (2016) \\
\hline 4 & $\begin{array}{l}\text { - Planning and carrying out investigations: an entry to learning and to teacher } \\
\text { professional development around NGSS science and engineering practices (2014) }\end{array}$ & $\begin{array}{l}\text { Assessing teacher education and professional development needs for the } \\
\text { implementation of integrated approaches to STEM education (2017) }\end{array}$ \\
\hline 5 & $\begin{array}{l}\text { - A comparative analysis of the relationship between learning styles and } \\
\text { mathematics performance (2014) }\end{array}$ & $\begin{array}{l}\text { Examining study habits in undergraduate STEM courses from a situative } \\
\text { perspective (2017) }\end{array}$ \\
\hline 6 & $\begin{array}{l}\text { + Research trends on argumentation in science education: a journal content analysis } \\
\text { from } 1998 \text { to } 2014 \text { (2015) }\end{array}$ & $\begin{array}{l}\text { + The role of visual representations in scientific practices: from conceptual } \\
\text { understanding and knowledge generation to "seeing" how science works (2015) }\end{array}$ \\
\hline 7 & $\begin{array}{l}\text { + STEM learning through engineering design: fourth-grade students' investigations in } \\
\text { aerospace (2015) }\end{array}$ & $\begin{array}{l}\text { Supporting integrated STEM in the elementary classroom: a professional } \\
\text { development approach centered on an engineering design challenge (2017) }\end{array}$ \\
\hline 8 & $\begin{array}{l}\text { + Refining questionnaire-based assessment of STEM students' learning strategies } \\
\text { (2015) }\end{array}$ & $\begin{array}{l}\text { The effects of an afterschool STEM program on students' motivation and } \\
\text { engagement (2017) }\end{array}$ \\
\hline 9 & $\begin{array}{l}\text { + The importance of context: an exploration of factors influencing the adoption of } \\
\text { student-centered teaching among chemistry, biology, and physics faculty (2015) }\end{array}$ & $\begin{array}{l}\text { - A comparative analysis of the relationship between learning styles and } \\
\text { mathematics performance (2014) }\end{array}$ \\
\hline 10 & $\begin{array}{l}\text { + Studying technology-based strategies for enhancing motivation in mathematics } \\
\text { (2014) }\end{array}$ & $\begin{array}{l}\text { - The teachers' role in developing, opening, and nurturing an inclusive STEM- } \\
\text { focused school (2016) }\end{array}$ \\
\hline
\end{tabular}


Table 9 Top 10 most accessed publications in 2018

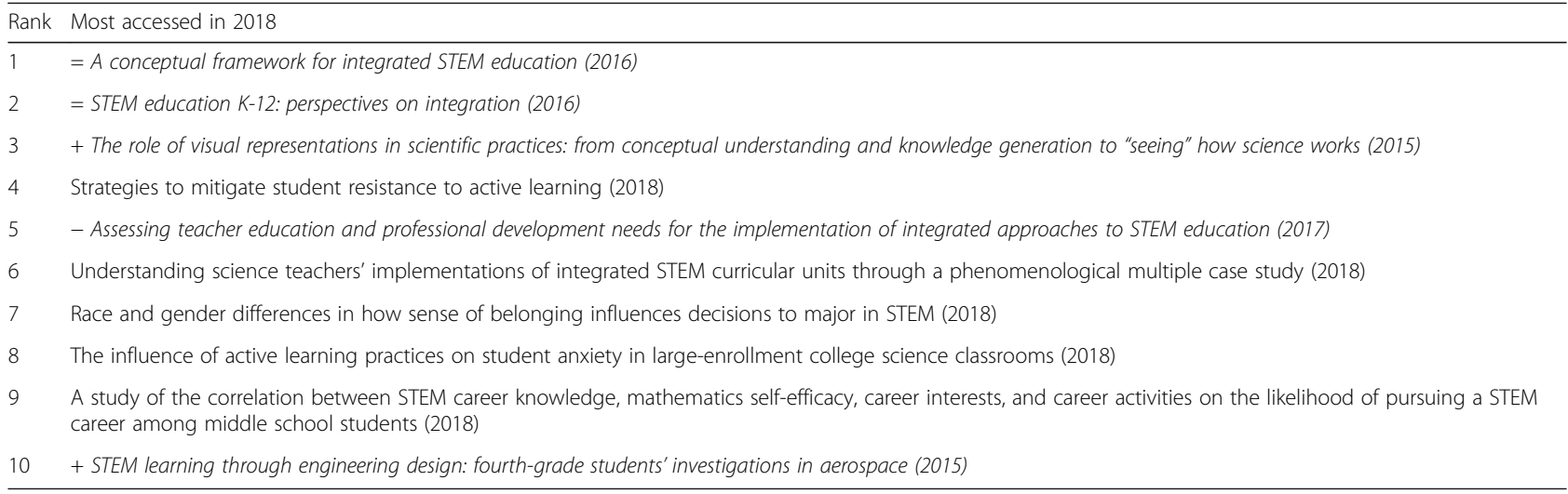

\section{Acknowledgements}

The author would like to thank Marius Jung and other staff at Springer Nature for their support of providing relevant data and valuable feedback on earlier versions of this editorial, and Yu Xiao for helping code and crosscheck the publications' research topics.

\section{Authors' contributions}

$Y L$ initiated to analyze the data and draft the manuscript. JEF reviewed the drafts and contributed to the draft revisions. KW helped with the data coding and reviewed the manuscript drafts. All authors read and approved the final manuscript.

\section{Funding}

Not applicable

\section{Availability of data and materials}

The data and materials used and analyzed for the editorial were these articles published in this journal or were provided by Springer. Journal article information is publicly available at the journal's website (https://

stemeducationjournal.springeropen.com)

\section{Competing interests}

The authors declare that they have no competing interests.

\section{Author details}

${ }^{1}$ Texas A\&M University, College Station, TX 77843-4232, USA. ${ }^{2}$ Ohio State

University, Columbus, $\mathrm{OH}$ 43210, USA.

Received: 12 May 2019 Accepted: 30 May 2019

Published online: 14 June 2019

\section{References}

Howard, G. S., Cole, D. A., \& Maxwell, S. E. (1987). Research productivity in psychology based on publication in the journals of the American Psychological Association. American Psychologist, 42(11), 975-986.

Hynes, M. M., Mathis, C., Purzer, S., Rynearson, A., \& Siverling, E. (2017). Systematic review of research in P-12 engineering education from 2000-2015. International Journal of Engineering Education, 33(1B), 453-462.

Li, Y. (2014). International Journal of STEM Education - a platform to promote STEM education and research worldwide. International Journal of STEM Education, 1, 1. https://doi.org/10.1186/2196-7822-1-1.

Li, Y. (2018a). Four years of development as a gathering place for international researchers and readers in STEM education. International Journal of STEM Education, 5, 54. https://doi.org/10.1186/s40594-018-0153-0.

Li, Y. (2018b). Journal for STEM Education Research - promoting the development of interdisciplinary research in STEM education. Journal for STEM Education Research, 1(1-2), 1-6. https://doi.org/10.1007/s41979-018 0009-z

Lin, T.-J., Lin, T.-C., Potvin, P., \& Tsai, C.-C. (2019). Research trends in science education from 2013 to 2017: A systematic content analysis of publications in selected journals. International Journal of Science Education, 41(3), 367-387.
Tsai, C.-C., \& Wen, L. M. C. (2005). Research and trends in science education from 1998 to 2002: A content analysis of publications in selected journals. International Journal of Science Education, 27(1), 3-14.

\section{Publisher's Note}

Springer Nature remains neutral with regard to jurisdictional claims in published maps and institutional affiliations.

\section{Submit your manuscript to a SpringerOpen ${ }^{\circ}$ journal and benefit from:}

- Convenient online submission

- Rigorous peer review

- Open access: articles freely available online

- High visibility within the field

- Retaining the copyright to your article

Submit your next manuscript at $\boldsymbol{\nabla}$ springeropen.com 